\title{
Situação atual do IPTU no Rio de Janeiro e sua possível reforma
}

\author{
Pedro Humberto Bruno de Carvalho Júnior ${ }^{1}$
}

\begin{abstract}
Resumo
O artigo analisa a situação atual do IPTU no Município do Rio de Janeiro em estudo comparativo com outras grandes cidades brasileiras, enfocando cinco fatores determinantes do desempenho da arrecadação: o cadastro imobiliário municipal, as avaliações imobiliárias, a adimplência, as isenções e as alíquotas. $\mathrm{O}$ artigo também discute os principais pontos da agenda de Reforma do IPTU carioca de forma a melhorar o seu desempenho e torná-lo mais justo. $\mathrm{O}$ estudo estimou que $70 \%$ dos domicílios cariocas estavam cadastrados, indicando possibilidade de melhora da qualidade e da abrangência do cadastro municipal de imóveis. Verificou-se uma tendência recente de promulgação de novas Plantas Genéricas de Valores (PGV) nas principais cidades brasileiras que vinham experimentando longo período sem atualização. No Rio de Janeiro a PGV é de 1997 e as avaliações têm estado em nível muito abaixo do mercado, com grandes distorções entre os bairros da cidade (em média entre $22 \%$ e $43 \%$ do valor de mercado em 2009). A adimplência tem historicamente se situado em $75 \%$, um bom indicador se comparado as demais cidades brasileiras (caso a política de isenções seja revista, poderá haver queda da adimplência a curto prazo). As isenções do IPTU foram bastante abrangentes em algumas principais cidades brasileiras. No Rio de Janeiro elas têm representado cerca de dois terços do cadastro desde 2000, o maior indicador entre as cidades analisadas e foi apontado juntamente com as avaliações como um grande responsável pelo mau desempenho do imposto na cidade. As alíquotas variaram enormemente entre as cidades selecionadas. No Rio de Janeiro, apesar das altas alíquotas, elas não foram capazes de compensar a defasagem avaliatória e as reduções na base de cálculo do IPTU. O imposto lançado costuma ser muito baixo para seguimento residencial e territorial, na maioria das vezes tonando-os isentos. $\mathrm{O}$ artigo analisou-se a proposta de reforma do IPTU divulgada pela Secretaria Municipal de Fazenda no final do ano 2012. A proposta prevê valores venais correspondentes a metade do valor de mercado, alíquotas progressivas entre $0,2 \%$ e $0,6 \%$ para residências, fim das amplas isenções e descontos e um período de transição que limite o aumento do imposto a $30 \%$ em cada exercício fiscal. O artigo destaca que a alta redução das alíquotas talvez impeça ganhos efetivos de arrecadação visto que as avaliações irão corresponder a metade do valor de mercado. O período de transição é muito importante para a aceitação política da reforma, mas ressalta-se que limites percentuais de aumento em valores de IPTU que antes eram simbólicos ocasionam baixo incremento \footnotetext{
Tributária na Universidade de Pretória.
}

${ }^{1}$ Pesquisador Licenciado do Instituto de Pesquisa Econômica Aplicada (IPEA), doutorando em Política
\end{abstract}


arrecadatório. O parcelamento do aumento em períodos fiscais subsequentes ou a aplicação do percentual somente quando o aumento superar determinado valor são medidas que podem ser tomadas para corrigir essa distorção. Por fim o artigo conclui que a Reforma do IPTU é um dos principais itens da agenda fiscal do município, possibilitando grande incremento da arrecadação e justiça fiscal. Porém, o período de transição deve ser muito bem aplicado e a estipulação em lei dos períodos que as Planta Genérica de Valores deve sem atualizadas impediriam a necessidade de uma grande reforma do IPTU.

Palavras-chave: economia do setor público; tributação imobiliária; avaliação imobiliária; federalismo fiscal.

\begin{abstract}
The article analyzes the property tax performance in the Municipality of Rio de Janeiro by comparing the other large Brazilian municipalities. It focuses on five revenues performance mainstay: the cadastre (tax roll), the valuation roll, the collection, the exemptions and reliefs and the tax rates. The article also discusses the main points on the agenda of property tax reform in Rio de Janeiro, in order to improve its performance and fairness. It was estimated that $70 \%$ of the households in Rio de Janeiro were under the tax roll which suggests potential improve the tax roll coverage and quality. The paper found a recent trend of updating the Valuation Roll among the largest Brazilian municipalities, which have passed long period without any updating. In Rio de Janeiro, the current Valuation Roll was set in 1997 and has been very outdated with great distortions among the areas in the municipality (an average between 22 to $43 \%$ of the market value in 2009.) The collection rate has been about $75 \%$, a good performance comparing to others Brazilian municipalities (however, if the exemptions policy were reviewed the collection rate may be decreased in a short run). The property tax exemptions were very comprehensive throughout Brazilian municipalities. In Rio de Janeiro, the exempted properties have represented two-third of the tax roll, the greatest index among the studied municipalities. The exemptions policy and the outdated valuation roll were pointed out as the main reason of the low property tax performance in Rio de Janeiro. The statutory tax rates greatly varied amongst the studied cities. Despite Rio de Janeiro having higher rates, these latter were not able to compensate the assessment gap and the tax reliefs and exemptions. The tax levied usually been very low for the residential and vacant land class of properties, most in cases became them property tax exempted. The paper analyzed the recent proposal of property tax reform by Municipal Tax Department of Rio de Janeiro presented in the end of 2012. The proposal establishes assessed values as being one half of the real market values, progressive tax rates between 0.2 to $0.6 \%$ (for residences), the end of the wide tax reliefs and exemptions and a transitional period which set a tax increase ceiling of $30 \%$ for each fiscal year. However, the paper highlights that the proposed statutory rates reduction may avoid real gains in property tax revenues due to the assessment would be just one half of the market value. The transitional period is very important to reduce the reform political fallout, however ceiling the tax increase under little values that are
\end{abstract}


usually levied can led to low gains in terms of revenues. The tax increase subdivision throughout the following fiscal years can be a better strategy to smooth out the political pressures of a tax reform. Finally, the paper concludes that the property tax reform is one of the main items on Rio de Janeiro fiscal agenda, which would enable effective gains in terms of revenues and fair taxation. However, the transitional period should be very well planned and the maximum period of valuation cycles should be established by law to avoid large periods with no valuation roll updating and therefore the need of a great tax reform.

Key words: public sector economics; property taxation; real estate appraisal; fiscal federalism.

\section{Introdução}

O Imposto Predial e Territorial Urbano (IPTU) é um imposto de competência dos municípios, mas sua administração tem sido bastante negligenciada pela maioria. Como resultado, sua arrecadação muitas vezes tem sido simbólica e muito abaixo do potencial, apesar de alguns casos de boas práticas. Esse cenário se agrava numa política atual de desoneração tributária promovida pelo governo federal e que afeta negativamente o nível de transferências governamentais. Por isso, para dar estabilidade às receitas municipais, o incremento da arrecadação própria, notadamente o IPTU tem sido um fator chave nas finanças públicas municipais. As políticas e instrumentos urbanos elencados pelo Estatuto das Cidades, a tributação das transferências imobiliárias pelo ITBI e das heranças pelo ITCM, a fixação de indenizações por desapropriação tanto pelo poder executivo, quanto pelo judiciário e o uso do Cadastro Municipal de Imóveis para efetivação de políticas urbanas e sociais são apenas alguns dos exemplos das externalidades de um bom funcionamento do IPTU, que inclui avaliações imobiliárias realistas e um cadastro moderno, abrangente e atualizado.

Com isso, o artigo almeja levantar algumas considerações importantes da situação do IPTU para o caso do Município do Rio de Janeiro, comparando-o com outras grandes cidades brasileiras e investigando as principais causas de seu baixo desempenho. O artigo se baseia em um estudo maior intitulado "Defasagem do IPTU no Município do Rio de Janeiro: uma proposta de reforma", publicado como o Texto para Discussão n ${ }^{\circ} 1.746$ pelo Instituto de Pesquisa Econômica Aplicada - IPEA.

O caso para o Rio de Janeiro é ainda mais importante porque a cidade tem experimentado, desde 2008, um processo de elevada aceleração do preço dos imóveis e 
será palco de dois grandes eventos internacionais: a Copa do Mundo de 2014 e os Jogos Olímpicos de 2016. Estes eventos têm levado à realização de grandes investimentos urbanos, que irão afetar, sobremaneira, a valorização de certas áreas e a desigualdade espacial. A tributação imobiliária será um importante instrumento para financiar esses investimentos e reduzir a iniquidade.

O artigo se divide em oito seções, além desta introdução e das considerações finais. Em primeiro lugar, artigo analisa, de forma concisa, as razões para o desempenho do IPTU no Município do Rio de Janeiro, dentro dos cinco principais pilares que determinam a arrecadação do imposto e sobre o qual o poder municipal tem discricionariedade: o cadastro municipal de imóveis (seção 1), as avaliações imobiliárias (seção 2), o nível de inadimplência (seção 3), a abrangência das isenções (seção 4) e o sistema de alíquotas (seção 5). A seção 6 analisa os indicadores do IPTU nas principais capitais estaduais, em termos per capita, por PIB e como participação nas receitas municipais. As duas últimas seções (seções 7 e 8) analisam, respectivamente, os problemas atuais do IPTU no Rio de Janeiro e uma proposta inicial de reforma levantada pela Secretaria Municipal de Fazenda e divulgada pela mídia no final de 2012.

\section{Os Cadastros de Imóveis}

Ter um cadastro municipal de imóveis abrangente e com informações atualizadas é condição fundamental para um bom desempenho da arrecadação do IPTU. Os cadastros obsoletos e desatualizados não refletem a realidade urbana do município. Hoje em dia, os cadastros de imóveis podem ter um sistema de dados georreferenciados, constituindo uma grande ferramenta do planejamento urbano e em políticas habitacionais e sociais. Infelizmente, informações sobre os cadastros ainda são pouco divulgadas pelos municípios. Apenas a pesquisa "Perfil dos Municípios Brasileiros" de 1999 e 2004, publicada pelo IBGE, mapeou algumas informações dos cadastros municipais, dados que já estão ultrapassados. Devido aos trabalhos de recadastramento e georreferenciamento empreendidos por muitos municípios, recentemente, a situação dos cadastros vem se alterando de forma extraordinária. O artigo tentou estimar a abrangência dos cadastros, elaborando a Tabela 1, no qual compara o número de unidades cadastradas com dados censitários de 2010, em algumas capitais estaduais. 
Tabela 1

Propriedades Cadastradas e Recenseadas em oito principais cidades brasileiras, 2010.

\begin{tabular}{lrrrr}
\hline Município & $\begin{array}{r}\text { Unidades } \\
\text { Cadastradas }\end{array}$ & $\begin{array}{r}\text { Domicílios } \\
\text { Recenseados } \\
\mathrm{A}\end{array}$ & $\begin{array}{r}\text { Estab. Comerciais } \\
\text { Recenseados } \\
\mathrm{C}\end{array}$ & $\begin{array}{r}\text { Razão } \\
\text { A/(B + C) }\end{array}$ \\
\hline Rio de & 1.805 .818 & 2.406 .815 & 201.302 & $69 \%$ \\
Janeiro & 2.834 .896 & 3.898 .745 & 577.190 & $72 \%$ \\
São Paulo & 736.678 & 827.233 & 95.388 & $80 \%$ \\
Brasília & 575.436 & 846.488 & 111.866 & $60 \%$ \\
Belo & 515.844 & 634.538 & 102.855 & $70 \%$ \\
Horizonte & 507.719 & 574.039 & 94.827 & $76 \%$ \\
Curitiba & 459.740 & 779.826 & 68.170 & $54 \%$ \\
Porto Alegre & 467.700 & 511.191 & 25.170 & $87 \%$ \\
Fortaleza & & & \\
Manaus & &
\end{tabular}

Fonte: Secretarias Municipais de Finanças e Fazenda, Censo Demográfico 2010/IBGE, Cadastro Central de Empresas 2010/IBGE.

Conforme se observa na Tabela 1, em 2010, estima-se que ao redor de $70 \%$ dos domicílios existentes no Município do Rio de Janeiro estejam cadastrados. Esse indicador reflete a informalidade urbana, embora não haja impedimento legal para que esses assentamentos informais sejam cadastrados pela prefeitura. Comparando-se com os dados do Censo Demográfico de 2000, a abrangência do cadastro foi de $64 \%$, o que demonstra certa estabilidade. Porém, algo interessante acontece quando se analisa apenas o universo de domicílios com esgotamento sanitário, por rede geral e coleta de lixo. Enquanto em 2000, 90\% destes eram cadastrados, em 2010 esse indicador foi de $73 \%$. Isso demonstra que os recentes investimentos públicos em saneamentos realizados não estão sendo traduzidos no cadastramento dos domicílios beneficiados. Analisando os dados de outras cidades brasileiras, observa-se que o indicador se situou entre $54 \%$ (Fortaleza) a $87 \%$ (Manaus $^{2}$ ) o que demonstra grande heterogeneidade entre as cidades selecionadas.

\footnotetext{
${ }^{2}$ Manaus apresentava uma das piores coberturas do cadastro municipal de imóveis entre as capitais estaduais até o ano de 2010, quando então foi realizado um novo recadastramento com dados georreferenciados.
} 


\section{As Avaliações Imobiliárias}

As avaliações imobiliárias são um dos mais importantes fatores no desempenho da arrecadação do IPTU e deveriam refletir, em tese, no valor de mercado dos imóveis. Elas são realizadas pelo executivo municipal e devem ser submetidas à Câmara de Vereadores, através de um projeto de lei denominado Planta Genérica de Valores (PGV). Nas Câmaras de Vereadores há forte pressão política para não aprovação ou alteração de um projeto de lei da PGV, principalmente quando o lapso temporal entre a última PGV em vigor é elevado e uma atualização ocasionaria um grande aumento da carga tributária.

Avaliações defasadas e pouco precisas se traduzem em menor base de cálculo do IPTU e consequente menor tributação. A defasagem e a pouca precisão podem tornar o sistema regressivo verticalmente (quando imóveis de maior valor de mercado são efetivamente tributados em menor nível que imóveis de menor valor ${ }^{3}$ ), ou regressivo horizontalmente (quando imóveis de valor de mercado similares são sujeitos a tributações diferentes).

Os municípios têm ampla autonomia para elaborar suas PGVs. Em geral, a PGV é uma extensa lei onde cada logradouro, face de quadra ou outra divisão territorial adotada tem seus valores venais avaliados em metros quadrados. A maioria dos municípios brasileiros avalia as edificações e os terrenos separadamente, sendo o valor venal do imóvel o resultado desta soma, sujeita ainda aos fatores de correção contidos em lei (depreciação por idade, tipo ou uso do imóvel, condição do terreno, por exemplo). Outras cidades, como o Rio de Janeiro, apresentam a avaliação da edificação e do terreno conjuntamente, apenas diferenciando o uso do imóvel (valor do metro quadrado residencial, não residencial e territorial) e aplicando os fatores de correção previstos em lei. Em Brasília, Goiânia e Campo Grande, num outro extremo, cada edificação ou lote da cidade é avaliado isoladamente e inserido na PGV.

A Tabela 2, a seguir, mostra o máximo valor venal de edificações novas (sem depreciação por idade) e dos terrenos alcançados em capitais estaduais selecionadas, além dos anos em que foram realizadas as últimas atualizações das Plantas Genéricas de Valores.

\footnotetext{
${ }^{3}$ Tributação efetiva do IPTU significa a relação entre montante lançado do imposto e o valor de mercado do imóvel.
} 


\section{Tabela 2}

Valores venais máximos de edificações e terrenos e ano de instituição das últimas Plantas Genéricas de Valores em 12 capitais estaduais selecionadas, 2011 (em R \$ por metros quadrados)

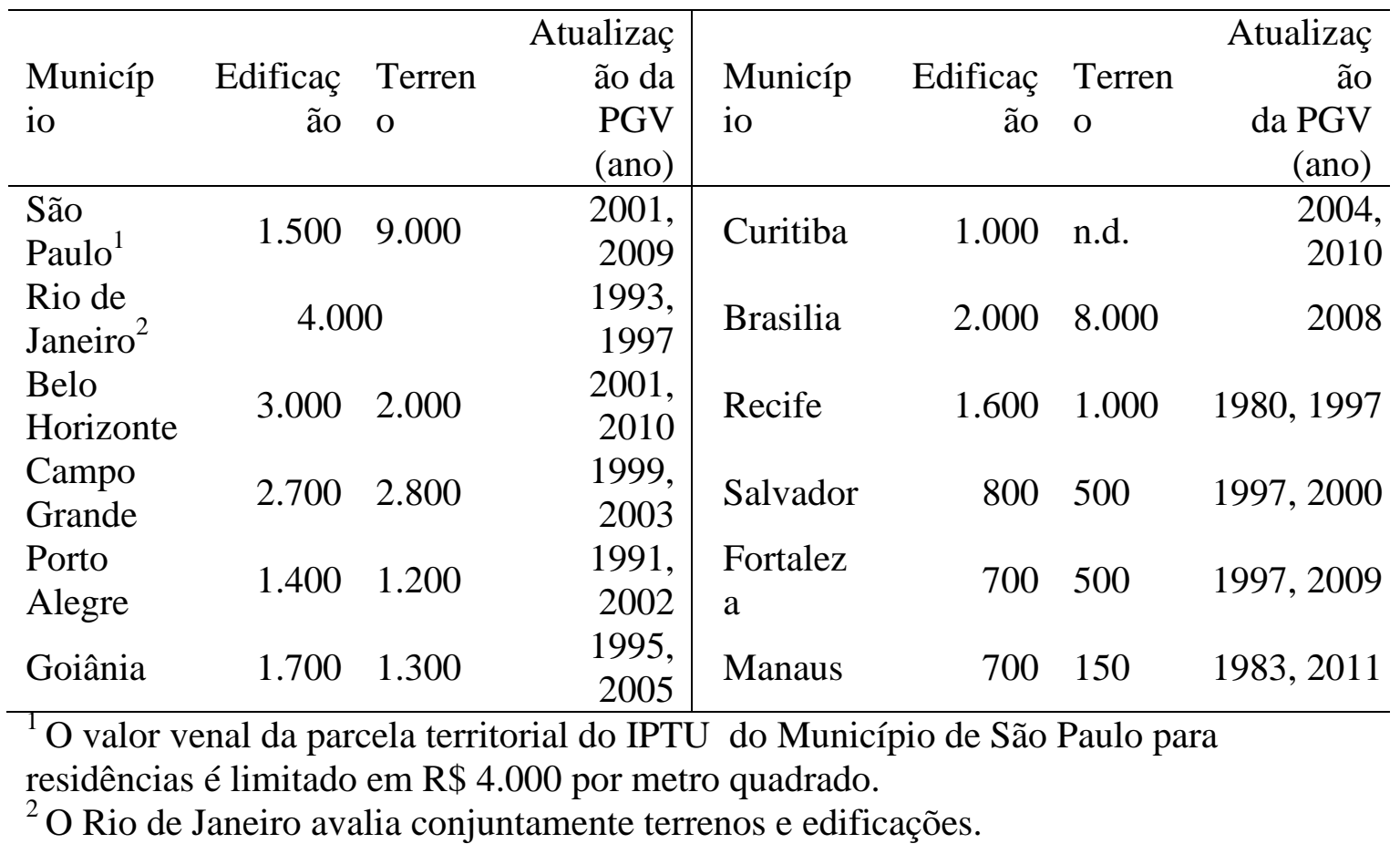

Observando-se os dados da Tabela 2 tem-se que os valores venais máximos inseridos nas Plantas Genéricas de Valores, nas capitais estaduais selecionadas, são bem mais baixos que os de mercado. Esses valores ainda costumam sofrer redução pela idade do imóvel ou uso residencial e a situação pode ser ainda pior. Em São Paulo o valor venal pode chegar até $\mathrm{R} \$ 10.500 / \mathrm{m}^{2}$ na Avenida Paulista, porém a legislação do município estabelece um teto para os terrenos residenciais em $\mathrm{R} \$ 4.000 / \mathrm{m}^{2}$, portanto as residências novas podem ter valor venal máximo de $\mathrm{R} \$ 5.500 / \mathrm{m}^{2}$ na capital paulista. No Rio de Janeiro, imóveis novos podem alcançar até $\mathrm{R} \$ 4.000 / \mathrm{m}^{2}$ na orla de São Conrado, embora esse valor sofra várias reduções até chegar à base de cálculo do IPTU (isso será discutido com mais detalhes nas seções posteriores). Os valores venais em Campo Grande no Mato Grosso do Sul podem chegar a $\mathrm{R} \$ 5.500 / \mathrm{m}^{2}$, o que pode ser um exemplo de boa prática em avaliação, já que é uma cidade média. Em oposição, cidades como Salvador, Fortaleza e Manaus, os valores venais máximos não chegam a R\$ $1.300 / \mathrm{m}^{2}$, o que mostra uma grande defasagem nas avaliações imobiliárias destas cidades e que são traduzidas em muito baixa arrecadação do IPTU. 
Observa-se também que há uma tendência dos valores venais das edificações serem maiores que os dos terrenos. No mercado a tendência é oposta, onde o valor Custo Unitário Básico (CUB) fornecido pelo Sindicato da Indústria da Construção Civil (SINDUSCON) para construções de alto padrão tem atingido valor entre R $\$ 2.000 / \mathrm{m}^{2} \mathrm{e}$ $\mathrm{R} \$ 2.500 / \mathrm{m}^{2}$ em 2012, sendo que o restante do valor do imóvel representaria o valor da sua localização, ou seja, o valor do terreno. Com exceção de São Paulo e Brasília, nas demais cidades analisadas, o valor venal máximo das edificações é maior ou aproximadamente igual ao valor máximo dos terrenos. Portanto o peso do padrão construtivo do imóvel costuma ser maior que o da localização no processo de avaliação imobiliária. Suspeita-se que esse fato acontece devido à facilidade de acesso aos valores dos custos unitários da construção civil, amplamente divulgado em revistas especializadas. Apurar o valor dos terrenos exige estudo técnico especializado dentro área geográfica do município e com isso, muitas vezes os municípios atualizam periodicamente somente o valor venal das edificações ${ }^{4}$.

A Tabela 2 também mostra os últimos anos de atualização das Plantas Genéricas de Valores. Apesar de uma tendência recente de novas atualizações como em São Paulo e Fortaleza (2009), Belo Horizonte e Curitiba (2010) e Manaus (2011), costuma haver um grande lapso temporal entre as atualizações da PGV. Algumas cidades como Rio de Janeiro, Recife, Porto Alegre e Salvador não atualizam a PGV há mais de uma década. Nas cidades que atualizaram a PGV recentemente, devido ao grande lapso temporal da última atualização, houve a necessidade, através das negociações políticas na Câmara de Vereadores, de limitar o aumento do valor lançado do IPTU em relação ao exercício fiscal anterior em $30 \%$ para as residências.

No processo de avaliação imobiliária é importante analisar os fatores de correção. Os fatores de correção são índices contidos em lei municipal que são aplicados aos valores originais das Plantas Genéricas de Valores de forma a ajustá-los e determinar o valor venal de um imóvel. Por exemplo, se a PGV aponta valores para imóveis novos, aos imóveis antigos existentes no cadastro pode ser aplicado um fator de depreciação por idade. Se um imóvel estiver localizado em um terreno sem acesso a

\footnotetext{
${ }^{4}$ Esse é o caso de Porto Alegre, onde o valor das edificações foi atualizado em 2002, mas o valor dos terrenos é o mesmo de 1991 (reajustado pela inflação). O município fluminense de Niterói é o caso mais emblemático conhecido, onde os valores venais das construções foram atualizados pela última vez em 2008, mas os terrenos apenas em 1976.
} 
uma via, ele pode sofrer uma redução do valor venal, assim como uma loja localizada em Shopping Center pode sofrer aumento. Os municípios tem ampla autonomia para fixar esses fatores de correção e seus valores. O fator de correção que mais costuma afetar o processo de avaliação é a depreciação por idade. A Tabela 3 abaixo mostra alguns exemplos do fator correção idade para cidades selecionadas.

Tabela 3

Incidência e fator de depreciação máximo empregados no cálculo do valor venal do IPTU em grandes cidades brasileiras por padrão construtivo

\begin{tabular}{|c|c|c|c|c|c|}
\hline Cidade & Incidência & $\begin{array}{c}\text { Resid. } \\
\text { padrão } \\
\text { alto a luxo }\end{array}$ & $\begin{array}{l}\text { Resid. } \\
\text { padrão } \\
\text { médio a } \\
\text { simples }\end{array}$ & $\begin{array}{l}\text { Salas } \\
\text { comerciais }\end{array}$ & $\begin{array}{c}\text { Lojas } \\
\text { comerciais }\end{array}$ \\
\hline Niterói & Não existe & \multicolumn{4}{|c|}{ Não existe } \\
\hline São Paulo & Edificação & $\begin{array}{l}80 \% \text { em } \\
60 \text { anos }\end{array}$ & $\begin{array}{l}80 \% \text { em } 40 \\
\text { anos }\end{array}$ & \multicolumn{2}{|c|}{$80 \%$ em 40 anos } \\
\hline Campinas & Edificação & \multicolumn{4}{|c|}{$60 \%$ em 60 anos } \\
\hline $\begin{array}{l}\text { Rio de } \\
\text { Janeiro }\end{array}$ & $\begin{array}{l}\text { Terreno e } \\
\text { edificação }\end{array}$ & \multicolumn{2}{|c|}{$50 \%$ em 50 anos } & $\begin{array}{l}35 \% \text { em } 60 \\
\text { anos }\end{array}$ & $\begin{array}{l}20 \% \text { em } 45 \\
\text { anos }\end{array}$ \\
\hline $\begin{array}{l}\text { Belo } \\
\text { Horizonte }\end{array}$ & Edificação & $\begin{array}{l}37 \% \mathrm{a} \\
60 \% \mathrm{em}\end{array}$ & $\begin{array}{l}58 \% \text { a } 80 \% \\
\text { em } 40 \text { anos }\end{array}$ & $\begin{array}{l}32 \% \text { a } 40 \% \\
\text { em } 40 \text { anos }\end{array}$ & $\begin{array}{l}25 \% \text { a } 53 \% \\
\text { em } 40 \text { anos }\end{array}$ \\
\hline $\begin{array}{l}\text { Campo } \\
\text { Grande }\end{array}$ & Edificação & \multicolumn{4}{|c|}{$\begin{array}{l}\text { Conservação: } 0 \% \text { se Novo, } 10 \% \text { se Bom, } 20 \% \\
\text { Regular e } 50 \% \text { se Péssima }\end{array}$} \\
\hline Vitória & Edificação & \multicolumn{4}{|c|}{$60 \%$ em 50 anos } \\
\hline Goiânia & Edificação & \multicolumn{4}{|c|}{$\begin{array}{c}\text { Conservação: } 0 \% \text { se Boa, 20\% se Regular, 30\% Ruim } \\
\text { e 40\% se Péssima }\end{array}$} \\
\hline Curitiba & Edificação & $\begin{array}{l}40 \% \text { em } \\
50 \text { anos }\end{array}$ & $\begin{array}{l}60 \% \text { em } 50 \\
\text { anos }\end{array}$ & \multicolumn{2}{|c|}{$40 \%$ a $60 \%$ em 50 anos } \\
\hline Brasília & Não Existe & \multicolumn{4}{|c|}{ Não existe } \\
\hline
\end{tabular}

Fonte: Legislações Tributárias Municipais (Elaboração do própria), apud Carvalho Jr (2012, p.82).

Com exceção do Rio de Janeiro, todas as cidades selecionadas aplicam o fator de depreciação por idade apenas no valor da edificação, o que estaria de acordo com as melhores práticas em avaliação imobiliária. O fato do Rio de Janeiro aplicar uma depreciação de até $50 \%$ para todo o valor do imóvel residencial pode levar a sérias distorções e regressividade avaliatória, principalmente em imóveis antigos localizados 
nas áreas mais valoradas. Em geral, na maior parte das cidades selecionadas, a redução se encontra entre $40 \%$ e $80 \%$ na parcela edificada das residências, dentro de um intervalo de tempo de 40 e 60 anos. Há exceções como em Niterói e Brasília, onde não há depreciação por idade e em Goiânia e Campo Grande, onde a depreciação se dá pelo estado de conservação do imóvel.

\section{A Adimplência}

A alta inadimplência do imposto imobiliário é bastante comum em países em desenvolvimento. $\mathrm{O}$ fato de ele ser competência do governo local torna alto o custo político de medidas como fiscalização e melhora da adimplência. Bahl e MartinezVasquez (2008) ressaltam que os índices de adimplência costumam ser muito baixos em países em desenvolvimento e que efetivamente, a única medida aplicada aos maus pagadores é a restrição da transferência da propriedade em débito. Essa realidade também acontece no Brasil. Apesar da lei oferecer várias medidas contra inadimplentes, como leilão público da propriedade, inserção da contribuinte no sistema de proteção ao crédito (SPC) e terceirização da dívida, elas são raramente aplicadas, principalmente em cidades pequenas e médias e para contribuintes residenciais. É bastante comum cidades pequenas e médias terem uma adimplência do IPTU menor que 40\%. Porém, como mostra a Tabela 4, em cidades maiores a adimplência se situou entre $65 \%$ e $88 \%$ em 2011 (com exceção de Manaus). Os resultados em 2011 são bem melhores que em 2000, na maior parte das cidades selecionadas, o que mostra que houve uma melhora geral na adimplência do IPTU. Ressaltam-se os casos de Campo Grande e Belo Horizonte, onde a adimplência era de apenas 55\% em 2000 e aumentou para mais de $80 \%$ em 2011. Por outro lado, a adimplência continua baixa em Salvador (70\%), Fortaleza (65\%) e Manaus (40\%).

\section{Tabela 4}

Nível de Adimplência do IPTU nas Dez Principais Cidades Brasileiras: 2000 e $2011(\mathrm{em} \%)$

\begin{tabular}{lrrcccr}
\hline Município & $\mathbf{2 0 0 0}$ & $\mathbf{2 0 1 1}$ & & Municípi & 2000 & $\mathbf{2 0 1 1}$ \\
\hline Curitiba & 80 & 75 & Alegre & Porto & 65 & 82 \\
\hline
\end{tabular}




\begin{tabular}{lcclcc}
\hline Rio de Janeiro & 75 & 80 & Goiânia & 70 & 70 \\
São Paulo & 86 & 88 & Salvador & 50 & 70 \\
$\begin{array}{l}\text { Campo } \\
\text { Grande }\end{array}$ & 55 & 82 & Fortaleza & 65 & 65 \\
$\begin{array}{l}\text { Belo } \\
\text { Horizonte }\end{array}$ & 55 & 88 & Manaus & 25 & 40 \\
\hline
\end{tabular}

Fonte: Perfil dos Municípios Brasileiros/IBGE (2000) e Secretárias Municipais de Fazenda ou Finanças (2011)

\section{As Políticas de Isenções e Reduções}

Os municípios também têm ampla autonomia para estabelecer os critérios e o nível das isenções e descontos do IPTU. Apesar das imunidades constitucionais para templos de qualquer culto, sindicatos, partidos políticos e órgãos públicos, por exemplo, as isenções concedidas a critério dos próprios municípios costumam ter impacto significativo no desempenho do IPTU. Apesar da motivação política de uma lei de isenção ou redução ser o aumento de justiça na tributação, na prática as políticas de isenções tem beneficiado um número muito grande de propriedades. A Tabela 5 mostra os principais critérios de redução e descontos em cidades selecionadas, bem como o percentual de propriedades isentas no cadastro.

\section{Tabela 5}

Principais Critérios Isenções e Reduções de IPTU e Proporção de Imóveis Isentos no Cadastro em Alguns Municípios Brasileiros, 2010.

\begin{tabular}{|c|c|c|}
\hline & & Proporção de \\
\hline Cidade & Principais isenções e reduções em 2008 & $\begin{array}{ll}\text { Isentos } & \text { no } \\
\text { Cadastro } & \\
\end{array}$ \\
\hline Porto Alegre & $\begin{array}{l}\text { * Aposentados e pensionistas de renda até } 3 \\
\text { SM; } \\
\text { * Valor venal até R \$ } 8 \text { mil. }\end{array}$ & $28 \%$ \\
\hline Curitiba & $\begin{array}{l}\text { * Valor venal até } \mathrm{R} \$ 28 \text { mil; } \\
\text { * Aposentados e pensionistas de renda até } 3 \\
\text { SM. }\end{array}$ & $15 \%$ \\
\hline São Paulo & $\begin{array}{l}\text { * Aposentados e pensionistas de renda até } 3 \\
\text { SM; } \\
\text { * Valor venal até R\$ } 70 \text { mil; } \\
\text { * Valor venal até } \mathrm{R} \$ 92,5 \text { mil se residencial; } \\
\text { * Desconto de R } \$ 37 \text { mil para valor venal até } \\
\text { R\$ } 185 \text { mil se padrão de construção }\end{array}$ & $39 \%$ \\
\hline
\end{tabular}




\begin{tabular}{|c|c|c|}
\hline \multicolumn{2}{|r|}{ simples ou médio } & \\
\hline $\begin{array}{l}\text { Rio de } \\
\text { Janeiro }\end{array}$ & $\begin{array}{l}\text { * Desconto de } 40 \% \text { para Valor Venal até } \mathrm{R} \$ \\
40 \text { mil; } \\
\text { * Desconto de } \mathrm{R} \$ 260, \mathrm{R} \$ 1.040 \text { e } \mathrm{R} \$ 3.636 \\
\text { para o IPTU residencial, não residencial e } \\
\text { territorial, respectivamente. }\end{array}$ & $65 \%$ \\
\hline $\begin{array}{l}\text { Belo } \\
\text { Horizonte }\end{array}$ & * Valor venal até $\mathrm{R} \$ 13$ mil & $14 \%$ \\
\hline Recife & $\begin{array}{l}\text { * Desconto de } 25 \% \text { a } 50 \% \text { para valor venal } \\
\text { até R\$ } 21 \text { mil; } \\
\text { * Isenção para proprietários de baixa renda } \\
\text { com imóvel até } 50 \mathrm{~m}\end{array}$ & $19 \%$ \\
\hline Fortaleza & * Valor venal até $\mathrm{R} \$ 21$ mil. & $20 \%$ \\
\hline Manaus & * Renda até $3 \mathrm{SM}$ & $8 \%$ \\
\hline Belém & * Valor venal até $\mathrm{R} \$ 16$ mil & $54 \%$ \\
\hline
\end{tabular}

Fonte: Legislações Tributárias Municipais/Secretarias Municipais de
Finanças/Fazenda; Carvalho Jr (2012)

Analisando-se os dados da Tabela 5, observa-se que os critérios de isenção ou redução de IPTU mais frequentes são para aposentados e pensionistas e para imóveis até determinado valor venal. Este último critério pode levar a várias iniquidades na tributação, apesar do objetivo inicial ser de isentar os imóveis de proprietários mais pobres. Em primeiro lugar, o que é bastante comum, a PGV pode estar defasada, fazendo com que a legislação isente propriedades valoradas. Em segundo lugar o IPTU pode ser considerado um "imposto cidadão" fazendo com que o contribuinte mais pobre também se sinta responsável pelos investimentos e gastos públicos em sua comunidade. Além disso, o carnê de pagamento do IPTU costuma ser o único comprovante de posse em comunidades mais pobres, com ausência de titulação formal da propriedade.

Analisando-se os dados das cidades selecionadas, a proporção de isentos varia de apenas $8 \%$ em Manaus até $65 \%$ no Rio de Janeiro ${ }^{5}$. Curitiba e Belo Horizonte com $15 \%$

\footnotetext{
${ }^{5}$ Essas duas situações extremas merecem uma análise mais profunda. Manaus reformou o IPTU em 2011, em que reduziu o nível de isenções a $8 \%$ do cadastro e reformulou parcialmente a PGV, porém a cidade ainda tem uma taxa de inadimplência que chega a $60 \%$ dos contribuintes. O Rio de Janeiro isenta $65 \%$ dos imóveis no cadastro, porém essa situação existe devido a uma reforma tributária ocorrida em 1999 com a declaração de inconstitucionalidade do sistema de alíquotas progressivas (que passaram a ser permitidas somente mais tarde pela Emenda Constitucional no 29 de 2000). Para não elevar abruptamente a carga tributária aos imóveis que antes eram aplicados as menores alíquotas do sistema progressivo, a solução encontrada foi conceder grandes descontos na avaliação imobiliária e no valor a ser pago de IPTU o que efetivamente isentou grande parte dos contribuintes.
} 
do cadastro isento são exemplos de poucas isenções. Por outro lado, São Paulo (40\%) e Belém (54\%) possui alta proporção de isentos.

\section{As alíquotas}

As alíquotas no IPTU não têm um papel tão determinante que as variáveis administrativas na arrecadação. Visto que a acurância do cadastro de imóveis e das avaliações imobiliárias, além do papel das políticas de isenções e reduções impactam mais significativamente a base de cálculo. Apesar das variáveis administrativas serem mais importantes, Bahl (2007) destaca que nos poucos países em desenvolvimento que possuem uma boa administração do imposto como a Indonésia, a alíquota é de apenas 0,5\%, muito baixa para ganhos efetivos na arrecadação. No Brasil, alíquotas residenciais muito baixas são encontradas em cidades do Centro-Oeste, como Brasília $(0,3 \%)$, Cuiabá $(0,4 \%)$ e Goiânia (entre $0,2 \%$ e $0,55 \%)$. A Tabela 6 mostra os valores e os critérios de variação de alíquotas de cidades selecionadas.

\section{Tabela 6}

Alíquotas do IPTU nas principais capitais estaduais, 2008

\begin{tabular}{|c|c|c|c|c|}
\hline Cidade & $\begin{array}{l}\text { Critério de Variação das } \\
\text { Alíquotas }\end{array}$ & $\begin{array}{l}\text { Residen } \\
\text { cial }\end{array}$ & $\begin{array}{l}\text { Não } \\
\text { Residen } \\
\text { cial }\end{array}$ & $\begin{array}{l}\text { Territo } \\
\text { rial }\end{array}$ \\
\hline $\begin{array}{l}\text { Porto } \\
\text { Alegre }\end{array}$ & $\begin{array}{l}\text { Alíquota Única para } \\
\text { Edificações } \\
\text { Progressiva para terrenos }\end{array}$ & 0,85 & 1,1 & $\begin{array}{r}0,95 \text { a } \\
6,0\end{array}$ \\
\hline Curitiba & Progressiva & 0,2 a 1,1 & $\begin{array}{r}0,35 \mathrm{a} \\
1,8 \\
\end{array}$ & $\begin{array}{r}1,0 \mathrm{a} \\
3,0 \\
\end{array}$ \\
\hline São Paulo & Progressiva & 0,8 a 1,6 & 1,2 a 1,8 & $\begin{array}{r}1,2 \mathrm{a} \\
1,8\end{array}$ \\
\hline $\begin{array}{l}\text { Rio de } \\
\text { Janeiro }\end{array}$ & Alíquota Única & 1,2 & 2,8 & 3,5 \\
\hline $\begin{array}{l}\text { Belo } \\
\text { Horizonte }\end{array}$ & $\begin{array}{l}\text { Progressiva para Residências } \\
\text { Alíquota Única para Não } \\
\text { Residencial } \\
\text { Seletiva para Terrenos }\end{array}$ & 0,8 a 1,0 & 1,6 & $\begin{array}{r}1,0 \text { ou } \\
3,0\end{array}$ \\
\hline Salvador & $\begin{array}{l}\text { Seletiva por Padrão de } \\
\text { Construção } \\
\text { Alíquota Única para Terrenos }\end{array}$ & 0,1 a 1,0 & 1,0 a 1,5 & 2,0 \\
\hline Recife & $\begin{array}{l}\text { Progressiva para Edificados } \\
\text { Alíquota Única para Terrenos }\end{array}$ & 0,6 a 1,4 & 1,0 a 2,0 & 3,0 \\
\hline Fortaleza & $\begin{array}{l}\text { Progressiva para Edificados } \\
\text { Seletiva para terrenos }\end{array}$ & 0,6 a 1,4 & 1,0 a 2,0 & $\begin{array}{r}1,0 \text { ou } \\
2,0 \\
\end{array}$ \\
\hline
\end{tabular}




\begin{tabular}{|c|c|c|c|c|}
\hline Manaus & Progressiva & 0,2 a 0,9 & 0,2 a 0,9 & $\begin{array}{r}1,0 \mathrm{a} \\
2,0 \\
\end{array}$ \\
\hline Belém & Progressiva & 0,3 a 0,6 & 0,5 a 2,0 & $\begin{array}{r}1,0 \mathrm{a} \\
3,5 \\
\end{array}$ \\
\hline Goiânia & $\begin{array}{l}\text { Seletiva por Localização para } \\
\text { Edificados } \\
\text { Sel. por Loc. e Melhorias para } \\
\text { terrenos }\end{array}$ & $\begin{array}{r}0,2 \mathrm{a} \\
0,55\end{array}$ & 0,5 a 1,0 & $\begin{array}{r}1,0 \mathrm{a} \\
7,0\end{array}$ \\
\hline Cuiabá & Alíquota Única & 0,4 & 0,4 & 2,0 \\
\hline $\begin{array}{l}\text { Campo } \\
\text { Grande }\end{array}$ & $\begin{array}{l}\text { Alíquota Única para } \\
\text { Edificados } \\
\text { Seletiva por melhorias para } \\
\text { terrenos }\end{array}$ & 1,0 & 1,0 & $\begin{array}{r}1,5 \mathrm{a} \\
3,5\end{array}$ \\
\hline Brasília & Alíquota Única & 0,3 & 1,0 & 3,0 \\
\hline
\end{tabular}

Fonte: Legislações Tributárias Municipais, Carvalho Jr (2012, 2009)

Observa-se que as alíquotas progressivas também são muito populares entre os municípios brasileiros, desde que passaram a ser permitidas pela Emenda Constitucional $\mathrm{n}^{\mathrm{o}} 29$ de 2000. De fato, alíquotas muito baixas (menores que 0,5\%) estão presentes em Brasília, Goiânia e Salvador. Por outro lado, no Rio de Janeiro e em São Paulo as alíquotas residenciais e não residenciais estão acima de 1\%. Alíquotas maiores costumam ser aplicadas para terrenos. Esse fato, por outro lado, não indica que os terrenos tenham uma tributação maior que os imóveis edificados, visto que as avaliações dos terrenos costumam ser bem menores que dos imóveis edificados. No Rio de Janeiro, por exemplo, o valor venal dos terrenos costuma ser em média $20 \%$ do valor venal dos imóveis edificados numa mesma localização. Além disso, aos terrenos, é concedido um grande desconto de R\$ 3.834 no imposto final a pagar, que torna $92 \%$ dos terrenos, cadastrados no Município do Rio de Janeiro, isentos de IPTU. Campo Grande possui uma alta arrecadação per capita entre as capitais estaduais, sendo resultado de uma boa administração do imposto, com uma alíquota de $1 \%$.

\section{Os Indicadores de Arrecadação}

Elaborar um indicador para comparar o desempenho na arrecadação do IPTU entre municípios possui uma série de desafios. O melhor indicador para avaliar eficiência seria o montante arrecadado sobre a base tributária, ou seja, o valor de mercado total dos imóveis urbanos existentes no território municipal (excluído das imunidades 
constitucionais). Porém, não há dados disponíveis para o valor dos imóveis dentro de um município. Dados de arrecadação per capita, por renda ou por PIB municipal podem ser utilizados como uma aproximação, considerando que cidades mais populosas e com maior PIB tenham imóveis mais valorados.

Esses indicadores devem ser vistos com cuidado, porque existem cidades populosas, porém com alto índice de pobreza (imóveis de baixo valor), como por exemplo, os municípios metropolitanos de Nova Iguaçu (RJ), São Gonçalo (RJ) ou Jaboatão dos Guararapes (PE). Por outro lado, há cidades com elevada produção industrial e extrativista (maior PIB municipal), mas que não expressa uma maior base tributária do IPTU. Seria o caso dos municípios de Campos dos Goytacazes (RJ), Duque de Caxias (RJ) ou Camaçari (BA). Finalmente municípios que se localizam no litoral ou em cidades turísticas costumam ter elevado número de imóveis de veraneio, mas com baixa população residente e atividade econômica. Seria o exemplo de Guarujá (SP) e Armação de Búzios (RJ). Essas cidades possuem alto indicador de arrecadação per capita ou por PIB de IPTU, mas não se pode afirmar que são eficientes. Já a participação do IPTU nas receitas correntes, pode ser um bom indicador de desempenho, considerando o alto nível de transferências governamentais recebidas pelos municípios. Com isso, naqueles onde a participação do IPTU for mais expressiva, poderia indicar maior eficiência.

Será analisada a evolução da arrecadação per capita, por PIB municipal e a participação do IPTU nas receitas correntes nas principais cidades brasileiras, o que diminui o viés que pode ocorrer em determinadas cidades, como citado anteriormente. Na Tabela 7 se observa a evolução destes indicadores.

\section{Tabela 7}

Indicadores de Desempenho na Arrecadação do IPTU 13 principais cidades brasileiras, 2000-2010, por PIB (em \%), por participação nas Receitas Correntes (em \%) e per capita (em R \$ de dez/2011, IPCA).

\begin{tabular}{|c|c|c|c|c|c|c|c|c|c|}
\hline \multirow[t]{2}{*}{ Município } & \multicolumn{3}{|c|}{$\begin{array}{c}\text { IPTU por PIB } \\
(\%)\end{array}$} & \multicolumn{3}{|c|}{$\begin{array}{l}\text { IPTU nas Receitas } \\
\text { Correntes }(\%)\end{array}$} & \multicolumn{3}{|c|}{$\begin{array}{c}\text { IPTU per Capita } \\
\text { (em R\$ de } \\
\text { Dez/2011) }\end{array}$} \\
\hline & 2000 & 2005 & 2010 & 2000 & 2005 & 2011 & 2000 & 2005 & 2011 \\
\hline São Paulo & 0,83 & 0,90 & 0,91 & 17,1 & 15,9 & 14,3 & 269 & 291 & 400 \\
\hline Campinas & 0,82 & 0,89 & 0,80 & 13,8 & 14,9 & 11,1 & 216 & 261 & 293 \\
\hline Belo & 1,08 & 1,08 & 1,02 & 11,4 & 10,8 & 10,6 & 160 & 178 & 265 \\
\hline
\end{tabular}




\begin{tabular}{|c|c|c|c|c|c|c|c|c|c|}
\hline Horizonte & & & & & & & & & \\
\hline $\begin{array}{l}\text { Campo } \\
\text { Grande }\end{array}$ & 0,91 & 0,87 & 1,18 & 11,5 & 7,4 & 10,3 & 103 & 109 & 245 \\
\hline $\begin{array}{l}\text { Rio de } \\
\text { Janeiro }\end{array}$ & 0,78 & 0,86 & 0,75 & 13,0 & 12,9 & 10,2 & 216 & 225 & 240 \\
\hline $\begin{array}{l}\text { Porto } \\
\text { Alegre }\end{array}$ & 0,51 & 0,61 & 0,64 & 6,8 & 8,4 & 7,4 & 128 & 163 & 203 \\
\hline Goiânia & 0,76 & 0,89 & 0,93 & 9,5 & 9,1 & 9,3 & 115 & 136 & 186 \\
\hline Curitiba & 0,51 & 0,63 & 0,58 & 7,7 & 7,8 & 6,8 & 146 & 144 & 182 \\
\hline Brasília & 0,31 & 0,29 & 0,27 & 2,6 & 3,2 & 3,0 & 144 & 136 & 167 \\
\hline Recife & 0,64 & 0,73 & 0,62 & 8,5 & 8,2 & 7,2 & 89 & 107 & 129 \\
\hline Salvador & 0,70 & 0,52 & 0,54 & 10,3 & 7,6 & 6,7 & 75 & 58 & 91 \\
\hline Fortaleza & 0,43 & 0,42 & 0,43 & 5,5 & 4,6 & 4,4 & 45 & 48 & 70 \\
\hline Manaus & 0,09 & 0,10 & 0,10 & 2,2 & 2,2 & 1,9 & 19 & 22 & 29 \\
\hline
\end{tabular}

Fonte: Finanças do Brasil/Secretaria do Tesouro Nacional e PIB dos Municípios/IBGE

Primeiramente, a participação do IPTU no PIB municipal vem regredindo em Campinas, Rio de Janeiro, Curitiba e Recife. O indicador apresenta alguma estabilidade em São Paulo, Belo Horizonte, Salvador, Fortaleza e Manaus e tem crescido, de forma significativa, apenas em Campo Grande e Goiânia. Isso mostra que o crescimento da arrecadação do IPTU tem tido dificuldade em acompanhar o crescimento da atividade econômica, visto que atualizar a PGV é um processo político desgastante. Justamente no Rio de Janeiro e Recife a PGV não havia sido atualizada desde 1997. Destaca-se que a arrecadação nacional do IPTU tem correspondido historicamente a apenas 0,5\% do PIB brasileiro, um resultado bastante baixo para padrões internacionais. Municípios onde o IPTU corresponde a mais de $1 \%$ do PIB municipal poderiam ser considerados como casos de bom desempenho. Infelizmente, nas principais cidades brasileiras selecionadas, apenas em Belo Horizonte e Campo Grande o indicador ultrapassou esse nível. Num outro extremo, cidades como Brasília e Manaus têm arrecadado menos de 0,3\% do seu PIB.

A participação do IPTU no orçamento municipal vem decaindo em todas as cidades estudadas. Essa queda na participação é resultado do maior aumento das outras fontes de receitas, como transferências governamentais e do Imposto sobre Serviço (ISS). Conforme citação de Bahl (2008), o imposto imobiliário local sofre uma pressão política desproporcional a sua geração de receitas em países em desenvolvimento. De Cesare (2012) também destaca que os municípios têm direcionado no ISS os esforços na 
tributação própria, se esquecendo do IPTU. De fato, pela Tabela 7, em 2011, dentre as 12 cidades selecionadas, apenas São Paulo, Campinas, Campo Grande, Belo Horizonte e Rio de Janeiro, o IPTU tem representado pouco mais de $10 \%$ das Receitas Correntes, com tendência de queda. Em cidades como Brasília, Fortaleza e Manaus, o IPTU tem sido menos de $5 \%$ das receitas municipais.

Finalmente, o último indicador estudado da Tabela 7 é a arrecadação de IPTU per capita. Em todas as cidades analisadas, a arrecadação em termos reais aumentou, porém em níveis bem diferentes. Em Campo Grande houve um aumento real de 138\% entre 2000 e 2011, mas no Rio de Janeiro esse aumento foi de apenas 11\%. Isso mostra certa estagnação das receitas do IPTU no Rio de Janeiro, bem como em Salvador e Curitiba (crescimento real de $21 \%$ e $25 \%$, respectivamente). São Paulo com uma arrecadação per capita de $\mathrm{R} \$ 400$ é o melhor resultado encontrado. Em cidades como Belo Horizonte, Campo Grande, Rio de Janeiro e Porto Alegre a arrecadação per capita se situou entre R\$ 203 e R\$ 265. Num outro extremo, Salvador, Fortaleza e principalmente Manaus tem arrecadações muito baixas, em um nível abaixo de R 100 per capita.

\section{Atual Situação do IPTU Carioca}

O estudo até agora comparou 5 fatores determinantes na arrecadação do IPTU (cadastro, avaliação, adimplência, isenções e reduções, e alíquotas), bem como os indicadores comparativos de arrecadação do IPTU (per capita, por PIB municipal e por Receita Corrente). Com base nesses dados, quatro considerações podem ser feitas para o caso do Rio de Janeiro.

Em primeiro lugar, embora a amplitude do cadastro chegue a $70 \%$ dos domicílios recenseados pelo IBGE em 2010, uma atividade de recadastramento em que se amplie a cobertura do cadastro e se atualize e melhore a qualidade das informações físicas e legais dos imóveis é um item importante na agenda da reforma, além da inclusão de assentamentos informais. O georreferenciamento com a criação de um verdadeiro cadastro multifinalitário é a tendência atual de todas as reformas nos cadastros.

Em segundo lugar, o nível de adimplência do IPTU carioca, de cerca de 80\%, pode ser considerado como estando em bom nível, se comparado a muitas cidades brasileiras. 
A realização de leilões dos imóveis em dívida tem sido uma estratégia muito eficiente de aumentar o cumprimento das obrigações fiscais. Outras iniciativas que poderiam ser adotadas seriam a da inclusão do contribuinte nos cadastros do SPC e Serasa e/ou a de terceirização da dívida. De qualquer maneira, conforme Silvani (1992) a adimplência voluntária do contribuinte deve ser a principal política do governo municipal. Com isso, a realização de campanhas educativas, de forma a melhorar a cultura fiscal e a vinculação de parte do aumento da arrecadação diretamente nas comunidades, onde o imposto é arrecadado, tem se mostrado efetiva para aumentar a adimplência e reduzir as pressões políticas numa eventual reforma.

Em terceiro lugar, as avaliações imobiliárias, juntamente com a política de isenções são as principais responsáveis pela estagnação da arrecadação do IPTU no Rio de Janeiro. A Planta Genérica de Valores não é reajustada desde 1997 (Lei Municipal 2.585) e após esse período muita coisa mudou no mercado imobiliário. Regiões da cidade se valorizaram mais que outras, a desvalorização, devido à proximidade de comunidades que foram pacificadas, já não é mais tão acentuada e o crescimento do preço de imóveis, iniciado a partir de 2008, tornaram as avaliações feitas em 1997 totalmente fora da realidade atual. Apenas em termos comparativos, Belo Horizonte, que atualizou a PGV em 2010, possui cerca de 630 mil imóveis cadastrados, avaliados em R\$ 103,03 bilhões (ou 199\% do PIB Municipal). São Paulo, que atualizou a PGV em 2009, possui cerca de 3,07 milhões de imóveis cadastrados, avaliados em R \$ 499,7 bilhões (ou 112\% do PIB Municipal). Por outro lado, o Rio de Janeiro possuía cerca de 1,8 milhão de imóveis cadastrados em 2011, com uma estimativa de avaliação de cerca de R\$ 147 bilhões (ou 77\% do PIB Municipal).

Em último lugar, a política de isenções possui um efeito perverso por isentar $65 \%$ das residências cadastradas do pagamento do IPTU, gerando iniquidade na tributação e baixo dinamismo nas receitas. Como dito na seção 3, a política de isenções foi resultado de uma solução política devido à declaração de inconstitucionalidade das alíquotas progressivas em 1998. Com isso, a Lei Municipal 2.687/1999 instituiu a alíquota única de 1,2\% para residências, 2,8\% para imóveis não residenciais e 3,5\% para terrenos. Devido à necessidade de aplicação destas alíquotas únicas, isentaram-se as propriedades residenciais, onde eram aplicadas as menores alíquotas no sistema progressivo anterior (alíquotas residenciais que variavam de $0,15 \%$ a $3,55 \%$, conforme tamanho e 
localização do imóvel). De fato, comparando-se com outros municípios mostrados pela Tabela 5, o Rio de Janeiro foi aquele com a maior proporção de propriedades isentas em seu cadastro, índice muito superior a São Paulo (40\%) e Belo Horizonte (14\%).

A maioria dos municípios brasileiros usa uma metodologia tradicional de avaliação imobiliária chamada "Custo de Reprodução do Imóvel” onde há uma avaliação separada de terrenos (valor da localização) e das edificações. O valor venal final de um imóvel seria o resultado desta soma com a aplicação dos respectivos fatores de correção. Porém, a PGV do Rio de Janeiro determina conjuntamente o valor em metros quadrados para imóveis novos de uso residencial, não residencial e para terrenos em cada logradouro ou quadra de logradouro no município, conforme alguns exemplos do Apêndice A. Esses valores são fixados independentemente do padrão construtivo do imóvel, num sistema derivado do modelo chamado "Comparativo Direto de Dados de Mercado". Este modelo determina o valor dos imóveis com base em um modelo estatístico de preços hedônicos.

A PGV do Rio de Janeiro apresenta valores de metro quadrado para imóveis novos, aos quais são aplicados os fatores de correção de idade, posição e tipologia, apresentados no Apêndice B. Para 2011, sobre o imposto inicialmente calculado, ou seja, a base de cálculo aplicada à respectiva alíquota há um desconto de $\mathrm{R}$ \$ 277 (130 Ufirs) para unidades residenciais, R \$ 1.097 (515 Ufirs) para unidades não residenciais e R\$ 3.884 (1.800 Ufirs) para terrenos. Além disso, Unidades Autônomas Populares (UAP), isto é, residências com valor venal até R\$ 42.600 (20.000 Ufirs) e área menor que 100 metros quadrados, gozam de um desconto de $40 \%$ sobre o valor venal, o que de fato isenta as UAP do IPTU.

Com base nessas informações podemos ilustrar o processo de cálculo do IPTU de um imóvel hipotético no Município do Rio de Janeiro. Suponha um apartamento construído em 1966, com 60 metros quadrados, voltado para os fundos da via e localizado na Rua São Clemente em Botafogo.

a) Valor Venal $=$ Valor Residencial PGV $x$ Fator Idade $x$ Fator Tipologia $x$ Fator Posição x Tamanho

b) $R \$ 1.500 \times 0,55 \times 0,9 \times 0,9 \times 60=R \$ 40.095$

c) É uma UAP (valor venal menor que R\$42.600)? Sim, desconto de $40 \%$

d) Base de Cálculo: $R \$ 40.095$ x 0,6 = R\$24.057 
e) IPTU Calculado: $R \$ 24.057 \times 1,2 \%=R \$ 288$

f) IPTU Lançado: $R \$ 288-R \$ 277=R \$ 11$

Observa-se então que este apartamento localizado numa via valorizada do Rio de Janeiro, no bairro de Botafogo, pagaria anualmente um IPTU simbólico de R\$ 11 e uma Taxa de Coleta de Lixo no valor de R \$ 160, ambos cobrados no mesmo carnê. O valor venal foi correspondente a $18 \%$ do provável valor de mercado do imóvel (ao redor de 220 mil em 2011). Com as reduções aplicadas ao valor venal, a tributação efetiva foi praticamente nula.

A defasagem em relação ao mercado foi abordada no texto de Carvalho $\operatorname{Jr}$ (2012), onde foram analisadas 2.511 avaliações imobiliárias com a finalidade de concessão de crédito imobiliário, realizadas de forma terceirizada pela Caixa Econômica Federal em 2009. O trabalho comparou os valores venais oficiais com aqueles avaliados pela Caixa. Esses resultados são explicitados na Tabela 8.

\section{Tabela 8}

Distribuição na tributação do IPTU no Município do Rio de Janeiro, por Grupo de Bairros, em 2.511 imóveis financiados pela Caixa Econômica Federal no ano de 2009

\begin{tabular}{lrrrr}
\hline $\begin{array}{l}\text { Bairro Principal e } \\
\text { Adjacências }\end{array}$ & $\begin{array}{r}\text { Valor de } \\
\text { mercado } \\
\text { (mediana, } \\
\left.\mathrm{R} \$ \mathrm{~m}^{2}\right)\end{array}$ & $\begin{array}{r}\text { Valor Venal/ } \\
\text { Valor } \\
\text { mercado }\end{array}$ & $\begin{array}{r}\text { Proporção } \\
\text { de isentos } \\
(\mathrm{em} \%)\end{array}$ & $\begin{array}{r}\text { IPTU } \\
\text { Lançado/ } \\
\text { Valor } \\
\text { mercado }\end{array}$ \\
\hline Inhaúma & 929 & 27,7 & 87,7 & 0,04 \\
Santa Cruz & 934 & 32,2 & 90,9 & 0,00 \\
Pavuna & 1.036 & 26,0 & 88,6 & 0,01 \\
Madureira & 1.140 & 34,3 & 85,9 & 0,02 \\
Zona da & & & & \\
Leopoldina & 1.231 & 31,2 & 73,1 & 0,06 \\
Bangu & 1.157 & 25,9 & 87,4 & 0,02 \\
Grande Méier & 1.196 & 36,2 & 67,9 & 0,08 \\
São Cristóvão & 1.359 & 32,2 & 53,1 & 0,13 \\
Campo Grande & 1.396 & 22,9 & 86,7 & 0,02 \\
Irajá & 1.533 & 27,8 & 67,4 & 0,09 \\
Vila Isabel & 1.675 & 40,0 & 28,2 & 0,22 \\
Ilha do & & & & \\
Governador & 1.638 & 40,9 & 27,3 & 0,30 \\
Jacarepaguá & 1.732 & 33,9 & 44,3 & 0,16 \\
Méier & 1.661 & 33,4 & 46,6 & 0,15 \\
Centro & 2.077 & 24,2 & 58,3 & 0,11
\end{tabular}




$\begin{array}{lcrrr}\text { Tijuca } & 2.048 & 34,2 & 19,1 & 0,25 \\ \text { Recreio } & 2.591 & 33,9 & 4,1 & 0,34 \\ \text { Barra da Tijuca } & 3.606 & 43,0 & 0,0 & 0,46 \\ \begin{array}{l}\text { Copacabana } \\ \text { Lagoa/Leblon/Ip }\end{array} & 3.681 & 26,8 & 15,5 & 0,22 \\ \text { anema } & & & & \\ \end{array}$

Fonte: CAIXA e Legislação Tributária Municipal do Rio de Janeiro.

Os dados da Tabela 8 mostram que os valores venais no ano de 2009 estavam profundamente defasados em relação ao mercado e com tendência de piora no indicador porque os valores de mercado dos imóveis vêm subindo, bem acima da inflação (índice de reajuste anual dos valores venais). Há também uma elevada regressividade horizontal nas avaliações. Os valores venais médios dos bairros de Vila Isabel, Ilha do Governador e Barra da Tijuca representaram cerca de $40 \%$ do valor de mercado, mas nos bairros de Copacabana, Lagoa e Centro essa relação foi de 25\%. Diminuir a grande defasagem em relação ao mercado e a regressividade horizontal são as duas principais metas de uma eventual reforma no IPTU do Rio de Janeiro. O Apêndice A mostra os valores venais em algumas vias importantes no Rio de Janeiro e pode-se verificar algumas injustiças, as quais podemos citar (considerando que os valores contidos na PGV representam o preço do metro quadrado de apartamentos novos e de frente):

a) O valor não residencial padrão para Avenida Ministro Edgar Romero em Madureira e para a Rua São Clemente em Botafogo têm valores venais similares (cerca de $\mathrm{R} \$ 2.000 / \mathrm{m}^{2}$ ), mas Madureira é um bairro desvalorizado da Região Suburbana e Botafogo uma das zonas mais valorizadas da cidade;

b) O valor residencial padrão para Rua Cambaúba no Jardim Guanabara, para a Rua São Clemente em Botafogo e para a Rua Conde de Bonfim na Tijuca tem valores venais similares (entre $R \$ 1.200 / \mathrm{m}^{2}$ e $R \$ 1.500 / \mathrm{m}^{2}$ ), porém o valor de mercado do metro quadrado do Jardim Guanabara é bem inferior ao da Tijuca e Botafogo;

c) Imóveis residenciais localizados na orla de Copacabana (Avenida Atlântica), uma das zonas mais valorizadas da América Latina, possui em média um valor residencial padrão ${ }^{6}$ de apenas $\mathrm{R} \$ 2.900 / \mathrm{m}^{2}$;

d) Imóveis comerciais localizados na Avenida Rio Branco, a principal área com escritórios corporativos no Centro do Rio de Janeiro, possui um valor não

\footnotetext{
${ }^{6}$ Considerando que a maioria dos imóveis localizados na Avenida Atlântica foram construídos até a década de 1970, há um desconto de no mínimo 30\% sobre este valor devido ao fator de correção idade.
} 
residencial padrão de $\mathrm{R} \$ 2.900 / \mathrm{m}^{2}$. A via apresenta um parque imobiliário antigo e as salas comerciais podem sofrer uma redução de até $70 \%$ neste valor ${ }^{7}$.

A Tabela 8 também mostra que a proporção de isentos é bastante alta em bairros do subúrbio do Rio de Janeiro e quase nula na Barra da Tijuca e Recreio. Estas duas últimas regiões concentram imóveis mais novos e pela atual metodologia de avaliação, a idade do imóvel é um componente muito importante. É interessante notar que $15 \%$ dos imóveis da amostra, localizados em Copacabana (uma das áreas mais valorizadas do Rio de Janeiro), são isentos de IPTU. Isso aconteceu em virtude da idade mais antiga e do menor tamanho dessas unidades, o que impacta enormemente na avaliação.

A relação entre o valor lançado do IPTU e o valor de mercado do imóvel, o que nos fornece a tributação efetiva do imposto, variou bastante conforme os grupos de bairros. Em grande parte dos bairros do subúrbio a relação foi menor que $0,1 \%$ devido às isenções, mas esse percentual chegou a $0,3 \%$ nos imóveis da Ilha do Governador e em alguns bairros da Zona Sul (Lagoa, Leblon, Jardim Botânico e Ipanema) e foi de 0,46\% para Imóveis da Barra da Tijuca.

Uma reforma no IPTU do Rio de Janeiro também deveria rever o fator de correção idade e seu papel na defasagem avaliatória e iniquidade. $\mathrm{O}$ atual sistema desvaloriza a uma taxa de $1 \%$ até o limite de $50 \%$ o valor venal total dos imóveis residenciais. O mesmo estudo de Carvalho Jr. (2012), com base na amostra da Caixa Econômica, estimou que a desvalorização máxima por idade alcançaria $36 \%$ em 50 anos, caso os imóveis fossem localizados na Zona Sul, onde o peso da localização no valor de mercado do imóvel é mais elevado.

O fator de correção tamanho também deve ser revisto. $\mathrm{O}$ atual sistema reduz em $10 \%$ (fator de correção 0,9) se o imóvel tem menos de 100 metros quadrados, aumenta em 15\% (fator de correção 1,15) se o imóvel for maior que 300 metros quadrados e em $35 \%$ (fator de correção 1,35) se o imóvel for maior que 500 metros quadrados. Esse critério só pode ser justificado por motivação política na tentativa de sobretaxar imóveis maiores, já que o sistema de alíquotas anteriores, de 2000, era seletivo por tamanho e localização do imóvel. Em uma metodologia de avaliação imobiliária, onde a variável dependente seja o valor em metros quadrados, imóveis maiores teriam o valor do metro

\footnotetext{
${ }^{7}$ Esse valor é o resultado do fator de correção idade sala comercial (0,65 para 60 anos), fator de correção posição ( 0,9 para imóveis de fundos) e fator de correção tipologia ( 0,5 para salas comerciais).
} 
quadrado reduzido $^{8}$. No modelo de preços hedônicos, elaborado por Carvalho Jr (2012), há uma redução gradual do valor do metro quadrado, conforme se aumenta o tamanho do imóvel. Por exemplo, imóveis com 80 metros quadrados teriam uma redução estimada de $20 \%$ pelo modelo e imóveis com mais de 240 metros quadrados uma redução de $30 \%$. Caso não seja factível politicamente elaborar um sistema que valore mais o metro quadrado de unidades menores, o ideal seria extinguir o fator de correção tamanho numa eventual reforma tributária.

\section{A Necessidade de Reforma}

No final do ano de 2012, a Prefeitura do Rio de Janeiro divulgou para a grande imprensa a necessidade de reforma do IPTU carioca, onde a Secretaria Municipal de Fazenda iniciou os trabalhos para uma possível atualização da PGV. O entendimento da imprensa local sobre a necessidade de reforma do IPTU foi muito positiva, visto que no ano de 2008 houve um movimento organizado por alguns setores da sociedade contra o pagamento do IPTU, devido aos problemas da cidade com o slogan "IPTU: não pago e daí?" e que obteve certo apoio da mídia carioca. No ano anterior, em 2007, o Prefeito César Maia teve que voltar atrás numa tentativa de minirreforma do IPTU por Decreto Municipal, que mudava o critério de enquadramento das Unidades Autônomas Populares, a fim de diminuir o número de isentos ${ }^{9}$. Além disso, em 2009 houve uma campanha contra a introdução da Contribuição para Custeio da Iluminação Pública ${ }^{10}$ (Cosip) de certa forma também apoiada pela mídia. Apesar do Rio de Janeiro em 2009 ser a única capital estadual em que não era cobrado o tributo, houve uma forte oposição política à instituição da Cosip com uma série de liminares no Tribunal de Justiça do Rio de Janeiro, mas que no final declarou a constitucionalidade do tributo.

Felizmente a situação em 2012 foi bem diferente que as anteriores. Houve a percepção de que a cidade necessitava de investimentos de todas as esferas de governo e os impostos municipais financiaram os investimentos urbanos. O Rio de Janeiro precisava se reinventar, já que seria sede da Copa do Mundo de 2014 e dos Jogos Olímpicos de 2016. Cidades como São Paulo e Belo Horizonte já haviam reformado o

\footnotetext{
${ }^{8}$ Isso é intuitivo e fácil de entender. Um imóvel de apenas 35 metros quadrados (kitnet) teria o seu valor do metro quadrado superior a um vizinho com 200 metros quadrados (quatro quartos).

${ }^{9}$ Decreto Municipal 28.726/2007 que fora anulado pelo Decreto Municipal 28.957/2008.

${ }^{10}$ A Cosip foi instituída como tributo municipal no Brasil pela Emenda Constitucional no 39 de 2002 que adicionou o artigo 149-a Carta Magna.
} 
IPTU com ganhos significativos na arrecadação. Manter uma estrutura de IPTU arcaica, com um cadastro desatualizado e avaliações imobiliárias extremamente defasadas e injustas, seria um contrassenso.

Nas eleições municipais de 2012 os candidatos evitaram abordar o problema, devido ao impacto negativo das tentativas anteriores de reforma. Passadas as eleições, o assunto ressurgiu após uma série de reportagens publicadas no final de 2012 pelos jornais "O Globo", "O Extra" e "O Dia", os quais apresentaram os problemas do imposto, destacando o alto número de isentos. A reportagem do Jornal "O Extra" do dia 4 de novembro de $2012^{11}$ informou a proposta inicial de reforma pela Secretaria Municipal de Fazenda. Basicamente a proposta prevê:

a) Um sistema de alíquotas progressivas, que para residências estariam entre $0,2 \%$ e $0,6 \%$, para imóveis não residenciais entre $1 \%$ e $2 \%$ e para terrenos entre $1,2 \%$ e $2 \%$;

b) Novas avaliações compatíveis com o mercado, mas que para fins de tributação do IPTU representariam metade do valor de mercado do imóvel;

c) O fim do desconto aplicado às Unidades Autônomas Populares. O desconto no imposto final a pagar para imóveis residenciais deixaria de ser fixo (130 Ufirs) e passaria a ser progressivo, entre $\mathrm{R} \$ 15$ e $\mathrm{R} \$ 365$;

d) A consequente redução do número de residências isentas de $65 \%$ do cadastro para apenas $3 \%$ e de terrenos isentos de $92 \%$ para apenas $6 \%$;

e) Que o eventual aumento gerado pela reforma seria limitado a 30\% em cada exercício fiscal.

A proposta, sem sombra de dúvidas, representaria um grande avanço no atual sistema de tributação imobiliária do Rio de Janeiro, ao reduzir consideravelmente o número de imóveis isentos, ao fazer um sistema progressivo e ao aplicar uma medida de transição de tal forma que o contribuinte não suporte o aumento da carga tributária de uma só vez. O contribuinte precisa planejar seu orçamento para o aumento do imposto e também é importante que ele tenha tempo para perceber os maiores investimentos

\footnotetext{
${ }^{11}$ Disponível em: http://extra.globo.com/noticias/economia/prefeitura-vai-acabar-com-isencao-do-iptu6623747.html
} 
realizados em sua comunidade. Apesar das virtudes, três considerações podem ser feitas para aprimorar mais o debate.

Em primeiro lugar, a proposta deveria alterar os fatores de correção e idade e tamanho, que trazem injustiças na tributação. $\mathrm{O}$ fator de correção idade pode reduzir em até $50 \%$ o valor residencial padrão, beneficiando enormemente os imóveis antigos localizados em zonas valorizadas. O fator de correção tamanho sobretaxa o valor do metro quadrado de imóveis grandes ${ }^{12}$, embora no mercado o contrário aconteça.

Em segundo lugar, a redução da alíquota residencial de 1,2\% para um intervalo progressivo $0,2 \%$ a $0,6 \%$ parece ser muito acentuada, ainda mais se considerarmos que a base de cálculo será a metade do valor de mercado. Com isso a tributação efetiva máxima do novo sistema seria inferior a $0,3 \%{ }^{13}$. A Tabela 8 constatou, para o ano de 2009, uma tributação efetiva igual ou superior a este índice na Ilha do Governador $(0,3 \%)$, nos bairros mais valorizados da Zona Sul $(0,3 \%)$, no Recreio $(0,36 \%)$ e na Barra da Tijuca $(0,46 \%)$. A nova reforma pouco alteraria ou reduziria a tributação efetiva nestes bairros ${ }^{14}$. Além disso, entre as capitais estaduais, as novas alíquotas residenciais só seriam superiores nas cidades de Brasília $(0,3 \%)$, Cuiabá $(0,4 \%)$ e Goiânia $(0,55 \%)$, cidades que não adotam nenhum corte nas avaliações para fim de tributação do IPTU. As reformas recentes de São Paulo e Belo Horizonte não reduziram as alíquotas, mas aplicaram um limite de aumento da carga tributária. Portanto, não é necessária uma redução tão exagerada nas alíquotas, para adequar a carga tributária, se um período de transição for adotado.

É bem apontado pela literatura econômica que a tributação sobre terrenos deve ser mais alta que a tributação dos imóveis edificados, como forma de conceder incentivos ao uso da terra. Com isso, alíquotas bem maiores sobre terrenos devem ser aplicadas para corrigir esta distorção, o que não ocorre na proposta, onde as alíquotas territoriais (entre $1,2 \%$ e $2 \%$ ) seriam quase iguais às alíquotas não residenciais (entre $1 \%$ e $2 \%$ ). Devido à quase completa isenção dos terrenos na tributação atual do IPTU (92\% dos terrenos) e a questão social ligada ao desenvolvimento urbano, as alíquotas deveriam ser

\footnotetext{
${ }^{12}$ Para prover transparência ao sistema, a progressividade da carga tributária deve ser atribuída somente ao sistema de alíquotas, de forma que as avaliações sejam isonômicas e próximas ao valor do mercado. ${ }^{13}$ A referida reportagem do Jornal "O Extra" mostra que no novo modelo, um imóvel de valor venal de $\mathrm{R} \$ 300$ mil (valor de mercado de $\mathrm{R} \$ 600$ mil), seria tributado a $\mathrm{R} \$ 1.435$, o que representa uma alíquota efetiva de apenas $0,24 \%$.

${ }^{14}$ Esses resultados foram para o ano de 2009, devido aos posteriores aumentos do preço dos imóveis, a tributação efetiva deve ter se reduzido.
} 
bem superiores, não existir nenhuma redução no imposto final a pagar e tampouco alguma limitação no aumento da carga tributária dos terrenos.

A fixação de um limite de $30 \%$ para o aumento do imposto parece ser fundamental para a aceitação política e para o planejamento do orçamento familiar dos contribuintes, mas ela deve ser feita com bastante cuidado. Primeiramente esse limite deve aplicado para cada exercício fiscal e não apenas uma única vez (como na Reforma em São Paulo), evitando um aumento final de apenas 30\% em cima de valores que, muitas vezes, são simbólicos. Como muitos imóveis tinham tributação nula ou muito baixa no sistema antigo, um aumento anual de apenas R\$ 200 poderia representar $1.000 \%$ de aumento se o imposto anterior fosse de apenas $\mathrm{R} \$ 20$. Uma alternativa seria aplicar esse limite apenas quando o aumento superasse algum valor monetário. Ou então utilizar o modelo sul-africano, onde o aumento total da carga tributária, após a atualização da Planta de Valores, é divido em quatro exercícios fiscais em parcelas de $25 \%$. Com isso, se o aumento calculado fosse de $\mathrm{R} \$ 200$, o imposto lançado sofreria um aumento de $\mathrm{R} \$$ 50 por ano, dentro de quatro anos.

Por fim, seria pertinente aplicar a regra existente na legislação sul-africana e no Município de São Paulo (após a reforma de 2009), onde as atualizações devem ocorrer a cada 4 anos, de forma que não ocorra novamente a situação de grande defasagem, existente atualmente no Rio de Janeiro e da necessidade de uma grande reforma.

\section{Considerações finais}

O artigo comparou a situação do imposto no Rio de Janeiro com outras capitais estaduais em cinco questões relevantes: o cadastro imobiliário, as avaliações imobiliárias, a inadimplência, a política de isenções e descontos e o sistema de alíquotas. Além de analisar uma proposta inicial de reforma realizada pela Secretaria Municipal de Fazenda.

Estimou-se que o cadastro imobiliário fiscal abrange cerca de $70 \%$ dos domicílios entrevistados pelo último Censo Demográfico e alguma melhora pode ser feita em relação à abrangência de mais unidades (mesmo àquelas em situação informal) ao recadastramento, com a atualização das características físicas e legais e o uso da ferramenta de geoprocessamento, dotando o cadastro municipal de imóveis de múltiplas finalidades, para a execução das políticas públicas municipais entre as diversas 
secretarias existentes. A inadimplência também tem apresentado historicamente níveis baixos, se comparada com outras capitais estaduais, resultado sobretudo dos esforços administrativos da prefeitura e talvez do alto número de isentos, o que faz a arrecadação se concentrar num número menor de imóveis. É provável que com a redução das isenções a taxa de inadimplência aumente.

$\mathrm{O}$ artigo observou que as avaliações imobiliárias encontram-se profundamente defasadas. Para a realidade do ano de 2009, com base em uma amostra de imóveis residenciais avaliados pela Caixa Econômica Federal, elas se situavam entre 21\% e $43 \%$ do valor de mercado, com grande variabilidade entre os bairros da cidade. Ainda mais, devido à política de isenções e descontos, a carga tributária efetiva era baixíssima, menor que $0,15 \%$ nos bairros do Subúrbio e Zona Norte e entre 0,22\% e 0,43\% nos bairros mais valorizados da Zonal Sul, Ilha do Governador, Tijuca e Barra da Tijuca. Há uma tendência recente entre as principais cidades brasileiras de atualização da Planta Genérica de Valores, como os casos de São Paulo (atualização ocorrida em 2009 após 8 anos), Belo Horizonte (atualização ocorrida em 2010 após 9 anos), Fortaleza (atualização ocorrida em 2009 após 12 anos) e Manaus (atualização ocorrida em 2011 após 28 anos). O Rio de Janeiro é um candidato natural nessa agenda, pois a última atualização da PGV ocorreu em 1997. A cidade apresenta uma das áreas mais valorizadas da América Latina, mas os valores venais máximos na PGV que não chegam a $\mathrm{R} \$ 4.000$ por metro quadrado.

A política de isenções de IPTU é bastante abrangente para imóveis residenciais (65\% do cadastro) e terrenos ( $92 \%$ do cadastro). De fato, as isenções e os descontos para o IPTU residencial é tão significativo, que em 2011, os imóveis comerciais, apesar de perfazerem apenas $10 \%$ do cadastro, eram responsáveis por $60 \%$ da arrecadação. O número de isentos no Rio de Janeiro é bastante superior a outras capitais estaduais como Belo Horizonte (14\%), Fortaleza (20\%), Porto Alegre (28\%) ou São Paulo (40\%).

Esses fatores têm reduzido o desempenho da arrecadação do IPTU no Rio de Janeiro. De fato, a arrecadação não está conseguindo acompanhar o crescimento econômico da cidade e o crescimento das demais receitas municipais. Em 2005, o IPTU representava 0,86\% do PIB carioca, tendo caído para 0,75\% em 2010. Já a arrecadação que representava 12,9\% da receita corrente líquida em 2005, caiu para 10,2\% em 2010. Somente a arrecadação per capita em termos reais aumentou levemente, de R\$225 em 
2005 para R\$ 240 em 2010. Esses indicadores se encontram em um nível abaixo de cidades como São Paulo, Campinas, Belo Horizonte e Campo Grande, havendo potencial de incremento da arrecadação.

As atuais alíquotas no Rio de Janeiro podem ser consideradas elevadas. Um modelo de proposta inicial de reforma, divulgada pela Secretaria Municipal de Fazenda reduziria a alíquota residencial de 1,2\% para um intervalo progressivo entre $0,2 \%$ e 0,6\%, com a base de cálculo do imposto sendo metade do valor de mercado do imóvel. Apesar de terem sido embasadas em estudos da Secretaria Municipal de Fazenda, essa redução parece exagerada a primeira vista, pois levaria a uma tributação efetiva máxima de $0,3 \%$.

A atualização da PGV e o fim das isenções exigem um período de transição para que o aumento não onere o contribuinte abruptamente e a reforma seja factível politicamente. O trabalho discutiu alguns modelos que podem ser aplicados neste processo de transição, como a fixação de um limite para aumento do imposto em relação ao exercício fiscal anterior ou a divisão do aumento do imposto em períodos fiscais subsequentes. É importante frisar que se o aumento ocorrer sobre valores de IPTU, que antes eram simbólicos, a fixação de percentuais máximos de aumento em cima destes valores resultará em aumento simbólico. Deve-se aplicá-lo somente após o aumento ultrapassar certo valor monetário. O modelo de transição deve ser muito bem pensado para não perpetuar iniquidades.

Os resultados levantados indicam a necessidade de reforma do IPTU carioca, sendo um assunto relevante na agenda municipal, visto a alta defasagem dos valores venais em relação ao mercado, o elevado número de isenções e as grandes iniquidades devido à antiga Planta de Valores de 1997. O trabalho procurou mostrar a situação do Rio de Janeiro perante outras importantes cidades brasileiras e adicionou alguns pontos ao debate, sobre a inevitável reforma do IPTU que está para acontecer.

\section{Referências Bibliográficas:}

BAHL, Roy; MARTINEZ-VAZQUEZ, Jorge (2007). The Property Tax in Developing Countries: Current Practice and Prospects. Cambridge: Lincoln Institute of Land Policy (Working Paper). 
BAHL, Roy; WALlACE, Sally (2008). Reforming the Property Tax in Developing Countries: A New Approach. Atlanta: Andrew Young School of Policy Studies, Georgia State University (International Studies Program, Working Paper 08-19).

CARVALHO Jr, Pedro H. B (2009). Aspectos Distributivos do IPTU e do Patrimônio Imobiliário das Famílias Brasileiras. Rio de Janeiro, Ipea, (Texto para Discussão, n. 1.417).

CARVALHO JR., Pedro H. B. (2012). Defasagem do IPTU no Município do Rio de Janeiro: Uma Proposta de Reforma. Rio de Janeiro: IPEA (Texto para Discussão No 1746).

DE CESARE, Claudia (2012). Improving the Performance of the Property Tax in Latin America. . Cambridge: Lincoln Institute of Land Policy (Policy Focus Report).

IBGE - Instituto Brasileiro de Geografia e Estatística. Censo Demográfico 2010. Rio de Janeiro: IBGE, 2012.

Perfil dos municípios brasileiros: pesquisa de informações básicas municipais 2001. Rio de Janeiro: IBGE, 2002.

REPUBLIC OF SOUTH AFRICA. Department of Provincial and Local Government. (2004). Local Government: Municipal Property Rates Act, No.6 of 2004. Available: http://www.dplg.org.za

SILVANI. Carlos A (1992). Improving Tax Compliance. In: Bird, R.; de Jantsher, M. Casanegra (eds). Improving Tax Administration in developing Countries. Washington DC, IMF, (pp 276-287, 293-297) 


\section{APÊNDICE A}

Exemplos de valores venais de imóveis edificados novos de vias importantes no

Município do Rio de Janeiro. (em R $\$ / \mathrm{m}^{2}$, exercício 2010, Lei 2.539/1997)

\begin{tabular}{|c|c|c|c|c|}
\hline Bairro & Logradouro & $\begin{array}{r}\text { Valor } \\
\text { Venal } \\
\text { Residencial }\end{array}$ & $\begin{array}{r}\text { Valor Venal } \\
\text { Comercial }\end{array}$ & $\begin{array}{r}\mathrm{VV} \\
\text { Territorial } \\
\text { (lote padrão } \\
\mathbf{3 6 0} \mathbf{~ m}^{2} \text { ) }\end{array}$ \\
\hline \multirow{2}{*}{ Centro } & Av. Rio Branco & 1.355 & 2.916 & $\begin{array}{r}1.355- \\
6.187\end{array}$ \\
\hline & Av. Pres. Vargas & $\begin{array}{r}1.053- \\
1.077\end{array}$ & $\begin{array}{r}1.664- \\
2.777\end{array}$ & $\begin{array}{r}2.707- \\
5.800\end{array}$ \\
\hline São Conrado & $\begin{array}{l}\text { Av. Pref. Mendes de } \\
\text { Morais }\end{array}$ & 4.385 & 4.176 & 6.187 \\
\hline \multirow{2}{*}{ Copacabana } & Av. Atlântica & $\begin{array}{r}2.874- \\
2.994\end{array}$ & $\begin{array}{r}3.148- \\
4.448\end{array}$ & 4.562 \\
\hline & $\begin{array}{l}\text { Av. N. Sra. de } \\
\text { Copacabana }\end{array}$ & $\begin{array}{r}1.585- \\
1.783\end{array}$ & $\begin{array}{r}2.646- \\
3.079\end{array}$ & $\begin{array}{r}2.218- \\
3.041\end{array}$ \\
\hline \multirow{3}{*}{ Barra } & Av. Lucio Costa & $\begin{array}{r}2.395- \\
3.593\end{array}$ & $\begin{array}{r}2.281- \\
3.422\end{array}$ & $633-2.707$ \\
\hline & $\begin{array}{l}\text { Av. das Américas } \\
\text { (Barra) }\end{array}$ & $\begin{array}{r}1.592- \\
2.145\end{array}$ & $\begin{array}{r}2.851- \\
4.220\end{array}$ & $443-1.267$ \\
\hline & $\begin{array}{l}\text { Av. Pref. Dulcidio } \\
\text { Cardoso }\end{array}$ & 1.804 & 1.828 & 247 \\
\hline \multirow[b]{2}{*}{ Ipanema } & Av. Vieira Souto & 4.192 & 5.703 & 6.020 \\
\hline & $\begin{array}{l}\text { R. Visconde de } \\
\text { Pirajá }\end{array}$ & $\begin{array}{r}2.179- \\
2.251 \\
\end{array}$ & $\begin{array}{r}3.619- \\
4.288 \\
\end{array}$ & $\begin{array}{r}3.802- \\
4.436 \\
\end{array}$ \\
\hline \multirow{2}{*}{ Lagoa } & Av. Epitácio Pessoa & $\begin{array}{r}2.972- \\
3.066\end{array}$ & $\begin{array}{r}3.718- \\
4.060\end{array}$ & $\begin{array}{r}2.538- \\
4.753\end{array}$ \\
\hline & Borges de Medeiros & $\begin{array}{r}2.774- \\
3.066 \\
\end{array}$ & $\begin{array}{r}3.118- \\
3.703 \\
\end{array}$ & $\begin{array}{r}3.349- \\
3.929 \\
\end{array}$ \\
\hline \multirow[b]{2}{*}{ Leblon } & Av. Delfim Moreira & 4.311 & 5.475 & 6.178 \\
\hline & $\begin{array}{l}\text { Av. Ataulfo de } \\
\text { Paiva }\end{array}$ & 2.377 & 3.924 & 4.246 \\
\hline $\begin{array}{l}\text { Jardim } \\
\text { Botânico }\end{array}$ & R. Jardim Botânico & $\begin{array}{r}1.747- \\
1.981 \\
\end{array}$ & $\begin{array}{r}2.623- \\
2.920 \\
\end{array}$ & $\begin{array}{r}2.320- \\
2.475 \\
\end{array}$ \\
\hline \multirow{2}{*}{ Botafogo } & Praia de Botafogo & $\begin{array}{r}1.471- \\
1.839\end{array}$ & $\begin{array}{r}2.466- \\
2.692\end{array}$ & $\begin{array}{r}3.141- \\
3.333\end{array}$ \\
\hline & R. São Clemente & $\begin{array}{r}1.141- \\
1.563\end{array}$ & $\begin{array}{r}1.825- \\
2.281\end{array}$ & $\begin{array}{r}1.711- \\
2.281\end{array}$ \\
\hline \multirow{2}{*}{ Flamengo } & $\begin{array}{l}\text { R. Marquês de } \\
\text { Abrantes }\end{array}$ & $\begin{array}{r}1.655- \\
1.684\end{array}$ & $\begin{array}{r}2.235- \\
2.895\end{array}$ & $\begin{array}{r}1.856- \\
2.086\end{array}$ \\
\hline & Praia do Flamengo & $\begin{array}{r}2.108- \\
2.476\end{array}$ & $\begin{array}{r}2.692- \\
2.986\end{array}$ & 3.016 \\
\hline Laranjeiras & R. das Laranjeiras & $\begin{array}{r}1.563- \\
1.655 \\
\end{array}$ & $\begin{array}{r}2.007- \\
2.098 \\
\end{array}$ & $\begin{array}{r}1.045- \\
1.711 \\
\end{array}$ \\
\hline Tijuca & R. Conde de Bonfim & $\begin{array}{r}1.273- \\
1.445\end{array}$ & $\begin{array}{r}1.433- \\
3.193\end{array}$ & $\begin{array}{r}1.353- \\
2.218\end{array}$ \\
\hline
\end{tabular}




\begin{tabular}{|c|c|c|c|c|}
\hline Vila Isabel & $\begin{array}{l}\text { Boulevard } 28 \text { de } \\
\text { Setembro }\end{array}$ & $\begin{array}{r}1.103- \\
1.287\end{array}$ & $\begin{array}{r}1.674- \\
2.369 \\
\end{array}$ & $773-1.160$ \\
\hline \multirow[b]{2}{*}{ Recreio } & Av. Gláucio Gil & 1.592 & 1.779 & $221 / 247$ \\
\hline & Av. das Américas & $\begin{array}{r}1.242- \\
1.355\end{array}$ & $\begin{array}{r}1.482- \\
2.281\end{array}$ & $190-380$ \\
\hline \multirow{4}{*}{ Jacarepaguá } & $\begin{array}{l}\text { Av. Geremário } \\
\text { Dantas }\end{array}$ & $950-1.044$ & $\begin{array}{r}1.558- \\
2005\end{array}$ & $295-330$ \\
\hline & $\begin{array}{l}\text { Estr. dos } \\
\text { Bandeirantes }\end{array}$ & $723-819$ & $788-1.558$ & $53-123$ \\
\hline & Estr. Rio Grande & $818-1.051$ & $775-1.051$ & $88-98$ \\
\hline & $\begin{array}{l}\text { Rua Candido } \\
\text { Benício }\end{array}$ & $570-766$ & $877-1.420$ & $109-158$ \\
\hline \multirow[t]{2}{*}{ Ilha } & Rua Cambauba & $\begin{array}{r}1.096- \\
1.315\end{array}$ & $\begin{array}{r}1.559- \\
2.088\end{array}$ & $236-261$ \\
\hline & Estr. do Galeão & $855-986$ & $850-2.088$ & $130-377$ \\
\hline \multirow{2}{*}{$\begin{array}{l}\text { Grande } \\
\text { Meier }\end{array}$} & $\begin{array}{l}\text { Av. Dom Helder } \\
\text { Câmara }\end{array}$ & $716-819$ & $918-2.053$ & $139-208$ \\
\hline & Rua Dias da Cruz & $920-1.320$ & $\begin{array}{r}1.422- \\
2.436\end{array}$ & $86-165$ \\
\hline \multirow{2}{*}{ Madureira } & $\begin{array}{l}\text { Av. Min. Edgard } \\
\text { Romero }\end{array}$ & $690-767$ & $\begin{array}{r}2.121- \\
2.450\end{array}$ & $487-626$ \\
\hline & Estr. do Portela & $548-877$ & $\begin{array}{r}1.637- \\
2.572\end{array}$ & $522-696$ \\
\hline \multirow{2}{*}{$\begin{array}{l}\text { Vila da } \\
\text { Penha }\end{array}$} & $\begin{array}{l}\text { Av. Vicente de } \\
\text { Carvalho }\end{array}$ & $716-798$ & $835-1.169$ & $117-178$ \\
\hline & Av. Meriti & $665-716$ & $751-1.169$ & $65-139$ \\
\hline Penha & Av. Lobo Junior & $487-637$ & $584-835$ & $111-223$ \\
\hline \multirow{2}{*}{ Bonsucesso } & $\begin{array}{l}\text { Av. Teixeira de } \\
\text { Castro }\end{array}$ & $589-789$ & $556-904$ & $164-172$ \\
\hline & $\begin{array}{l}\text { Av. dos } \\
\text { Democráticos }\end{array}$ & $526-701$ & $584-904$ & $111-130$ \\
\hline Campo & Av. Cesário de Melo & 789 & $835-1.113$ & $104-133$ \\
\hline Grande & Estr. do Cabuçu & 657 & 654 & 66 \\
\hline $\begin{array}{l}\text { Bangu e } \\
\text { Outros }\end{array}$ & Av. Santa Cruz & $251-613$ & $399-821$ & $39-104$ \\
\hline
\end{tabular}




\section{APÊNDICE B}

Fatores de correção para cálculo do valor venal no Município de Rio de Janeiro em 2011

\begin{tabular}{|c|c|c|}
\hline \multicolumn{3}{|c|}{ I - Imóveis Edificados } \\
\hline \multirow{2}{*}{$\begin{array}{l}\text { 1) Fator Posição } \\
\text { a) Condição de } \\
\text { frente }\end{array}$} & Definição & Valor \\
\hline & Imóvel se localiza de frente a via & 1,0 \\
\hline $\begin{array}{l}\text { b) Condição de } \\
\text { fundos }\end{array}$ & Imóvel se localiza de fundos a via & 0,9 \\
\hline \multirow{2}{*}{$\begin{array}{l}\text { c) Condição } \\
\text { encravado } \\
\text { d) Condição em } \\
\text { vila }\end{array}$} & $\begin{array}{l}\text { Imóvel não se comunica com a via, exceto por } \\
\text { servidão ou passagem }\end{array}$ & 0,5 \\
\hline & Quando o imóvel se localiza em vila & 0,7 \\
\hline \multicolumn{2}{|c|}{ 2.1) Fator Tipologia Residencial } & Valor \\
\hline \multicolumn{2}{|c|}{ a1) Apartamento até $100 \mathrm{~m}^{2}$} & 0,9 \\
\hline \multicolumn{2}{|c|}{ a2) Apartamento entre 100 e $300 \mathrm{~m}^{2}$} & 1,0 \\
\hline \multicolumn{2}{|c|}{ a3) Apartamento entre 300 e $500 \mathrm{~m}^{2}$} & 1,15 \\
\hline \multicolumn{2}{|c|}{ a4) Apartamento acima de $500 \mathrm{~m}^{2}$} & 1,35 \\
\hline \multicolumn{2}{|c|}{ b) Casas (por região fiscal) } & 0,6 a 1,0 \\
\hline \multicolumn{2}{|c|}{ c) Apart-hotel } & 1,25 \\
\hline \multicolumn{3}{|c|}{ 2.2) Fator Tipologia Não Residencial } \\
\hline \multicolumn{2}{|c|}{ a) Lojas e shopping center } & $\begin{array}{l}0,55 \mathrm{a} \\
1,5\end{array}$ \\
\hline \multicolumn{2}{|c|}{$\begin{array}{l}\text { b) Salas comerciais, cinemas, hospitais, hotéis, escolas, clubes } \\
\text { esportivos e garagens }\end{array}$} & 0,5 a 0,6 \\
\hline \multicolumn{2}{|l|}{ c) Indústrias } & $\begin{array}{l}0,7 \text { ou } \\
0,75\end{array}$ \\
\hline
\end{tabular}

\section{3) Fator Idade Descrição \\ Valor}

a) Residencial

Depreciação de $1 \%$ ao ano, até o limite de $50 \%$ em 50 anos

0,99 a 0,5

Depreciação de $4 \%$ ao ano em intervalos de 7 anos,

b) Não $\quad 0,96$ a 0,8

Residencial somente a partir do $13^{\circ}$ ano de idade e limitada a $20 \%$ em 45 anos

c) Sala Comercial Depreciação de $5 \%$ ao ano em intervalos de 7 anos, somente a 0,95 a 0,65

partir do $13^{\circ}$ ano de idade e limitada a $35 \%$ em 60 anos

\section{II - Terrenos sem edificação}

\section{1) Fator Descrição}

a) Região A e B Subúrbio, Zona Portuária, Ilha

b) Região C Centro, Tijuca, Zona Sul, Barra, Recreio

Valor

c) Orla e Lagoa

Imóveis à beira-mar e na Lagoa

1,0 a 1,1

Aplicável a terrenos sobre os quais incidam restrições

$1,1 \mathrm{a}$

2) Fator Restrição

Legal

0,1 a 0,9

legais ao seu pleno aproveitamento

3) Drenagem Aplicável a terrenos inundáveis e alagados 


\section{0,1 a 0,9}

Aplicável a terrenos que apresentem características de

\section{4) Acidentação \\ 0,1 a 0,9 \\ acidentação topográfica impeditivas de seu pleno} aproveitamento)

Fonte: Lei Municipal nº 2.080/1993. 